\title{
PERAN KOMITE SEKOLAH DALAM MENINGKATKAN MUTU PENDIDIDIKAN
}

\author{
Muhammad Munawir Pohan \\ Penulis adalah Dosen Tetap di Universitas Al-Washliyah Labuhanbatu
}

\begin{abstract}
Abstrak
Since the enactment of decentralization of education, maximizing the role of school and community stakeholders has become very important in supporting the success of the education process in schools. The actualization form of education decentralization is realized by the existence of school committees which are expected to carry out their roles maximally in improving the quality of education. With the aspect seen, namely the role of the school committee as consideration, support, control, and role as mediator, the role is as a form of improving the quality of education in accordance with the mandate stated in the Minister of National Education Decree Number: 044 / U / 2002 dated April 2, 2002 Therefore, with regard to efforts to improve the quality of education, the government has actually issued a policy namely education autonomy. Educational autonomy as a form of education decentralization, gave birth to an important concept for the implementation of education. One of these important concepts is School-Based Management (SBM) which later gave birth to the School Committee as a manifestation of community participation in the world of education. The concept encourages school and community committees to become unified and complementary, and can even provide a color for the formulation of quality in schools. Society is an unequaled educational resource for education units. In community schools can be a foundation for improving and service quality education in the implementation of education.
\end{abstract}

Kata kunci: Komite, Sekolah, mutu.

\section{PENDAHULUAN}

Perkembangan ilmu pengetahuan telah membawa perubahan dihampir semua aspek kehidupan manusia dimana berbagai permasalahan hanya dapat dipecahkan kecuali dengan upaya penguasaan dan peningkatan ilmu pengetahuan. Selain bermanfaat bagi kehidupan manusia di satu sisi perubahan tersebut juga telah membawa manusia ke dalam era persaingan global yang semakin ketat. Agar mampu berperan dalam persaingan global kita harus menyadari peran penting dunia pendidikan.

Oleh karena itu meningkatan mutu pendidikan merupakan kenyataan yang harus dilakukan secara terencana, terarah, intensif, efektif dan efisien dalam proses pembangunan. Berbicara mengenai mutu pendidikan, sumber daya manusia memegang peran yang penting dalam proses meningkatan mutu pendidikan. meningkatan kualitas 
pendidikan merupakan suatu proses yang terintegrasi dengan proses meningkatan kualitas sumber daya manusia itu sendiri. Meningkatan kualitas pendidikan merupakan faktor utama yang menentukan keberhasilan pembangunan bangsa. Kualitas pendidikan memiliki arti bahwa lulusan pendidikan memiliki kemampuan yang sesuai, sehingga dapat memberikan kontribusi yang tinggi bagi pembangunan. mutu pendidikan sering diartikan sebagai karakteristik jasa pendidikan yang sesuai dengan kriteria tertentu untuk memenuhi kepuasan pengguna pendidikan, yakni peserta didik, orang tua, serta pihak-pihak berkepentingan lainnya.

Dalam menjaga mutu proses tersebut, diperlukan adanya quality controll yang mengawasi jalannya proses dan segala komponen pendukungnya yaitu masyarakat dan pemerintah. Pemerintahpun telah melakukan usaha untuk meningkatkan mutu pendidikan nasional, antara lain melalui berbagai kebijakan, pelatihan dan peningkatan kompetensi guru, pengadaan buku dan alat pelajaran, perbaikan sarana dan prasarana pendidikan, dan meningkatan mutu manajemen sekolah. Namun demikian, kenyataannya mutu pendidikan belum menunjukkan peningkatan yang berarti. Meskipun di sebagian sekolah, terutama di perkotaan, sudah berhasil melakukan peningkatan mutu pendidikan sehingga memberikan hasil yang sangat menggembirakan, namun sebagain besar lainnya justru masih sangat memprihatinkan. Pemberdayaan masyarakat merupakan prasyarat mutlak yang harus dipenuhi untuk keberhasilan setiap kegiatan pendidikan, karena masyarakat merupakan motor penggerak utama yang paling penting.

Oleh karena itu, berkenaan dengan upaya meningkatan mutu pendidikan pemerintah sebenarnya telah mengeluarkan kebijakan yaitu otonomi pendidikan. Otonomi pendidikan sebagai bentuk desentralisasi pendidikan, melahirkan konsep penting bagi penyelenggaraan pendidikan. Salah satunya konsep penting tersebut adalah Manajemen Berbasis Sekolah (MBS) yang kemudian melahirkan Komite Sekolah sebagai perwujudan partisipasi masyarakat di dunia pendidikan. Dari kebijakan otonomi tersebut sekolah memiliki wewenang untuk pembangunan pendidikan yang lebih berkualitas antara lain melalui pengembangan dan perbaikan kurikulum dan sistem evaluasi, perbaikan sarana pendidikan, pengembangan dan pengadaan materi ajar, serta pelatihan bagi guru dan tenaga kependidikan lainnya melalui konsep Manajemen Berbasis Sekolah (MBS). 
Pengembangan konsep MBS didesain untuk meningkatkan kemampuan sekolah dalam mengelola perubahan pendidikan kaitannya dengan tujuan keseluruhan, kebijakan, strategi perencanaan, inisiatif kurikulum yang telah ditentukan oleh pemerintah dan otoritas pendidikan. Pendidikan ini menuntut adanya perubahan sikap dan tingkah laku seluruh komponen sekolah; kepala sekolah, guru dan staf administrasi termasuk komite, orang tua dan masyarakat. Seluruh komponen sekolah harus pro aktif dan terlibat langsung dalam melaksanakan monitoring dan evaluasi terhadap segenap kebijakan pengelolaan sekolah yang bersangkutan dengan didukung oleh pengelolaan sistem informasi yang representatif dan valid. Akhir dari semua itu ditujukan kepada keberhasilan sekolah untuk menyiapkan pendidikan yang berkualitas/bermutu bagi masyarakat dan dapat memenuhi harapan dunia kerja.

Dalam implementasi konsep MBS sekolah memiliki tanggung jawab untuk mengelola dirinya berkaitan dengan permasalahan administrasi, keuangan dan fungsi setiap personil sekolah di dalam kerangka arah dan kebijakan yang telah dirumuskan oleh pemerintah. Yang aplikasinya dijalankan oleh sekolah bersama-sama komite dengan orang tua dan masyarakat. Salah satu wujud aktualisasi konsep Manajemen Berbasis Sekolah (MBS) adalah dibentuklah suatu badan yang mengganti keberadaan Badan Pembantu Penyelenggara Pendidikan (BP3) yakni Komite Sekolah melalui Keputusan Menteri Pendidikan Nasional nomor : 044/U/2002 tanggal 2 April 2002. Penggantian nama BP3 menjadi Komite Sekolah didasarkan atas perlunya keterlibatan masyarakat secara penuh dalam meningkatkan mutu pendidikan. Dari konsep tersebut peningkatan mutu harus menyeluruh, fleksibel dan berkesinambungan. Untuk meningkatkan mutu penyelenggaraan pendidikan di antaranya kebijakan pembentukan Komite Sekolah yang akhir-akhir ini menjadi agenda dalam dunia pendidikan di Indonesia. Menurut Edward sallis “Organisasi-organisasi yang menganggap serius pencapaian mutu, menyadari sebagian besar rahasia mutu berakar dari mendengar dan merespon secara simpatik terhadap kebutuhan dan keinginan para pelanggan dan klien".

Oleh karena itu keterlibatan masyarakat sangat penting sebagai sumber aspirasi dan tolak ukur pencapaaian mutu. Konsep ini cenderung disambut dan diapresiasi sebagai sebuah angin segar dalam proses perjalanan penyelenggaraan lembaga pendidikan dengan lebih mengintensifkan pelibatan masyarakat hal tersebut muncul ketika pemerintah menerapkan sistem desentralisasi pendidikan. Konsep Tersebut 
mendorong komite Sekolah dan masyarakat menjadi kesatuan dan saling melengkapi, bahkan dapat memberikan suatu warna terhadap perumusan mutu di sekolah. Masyarakat merupakan sumber daya pendidikan yang tiada bandingnya bagi satuan pendidikan. Di sekolah masyarakat dapat menjadi tumpuan atas peningkatan dan pelayanan mutu pendidikan dalam penyelenggaraan pendidikan. Tetapi pada dewasa ini masih banyak penyelenggaraan pendidikan yang masih mengesampingkan partisipasi masyarakat, pengadaan tenaga pendidik, sehingga penyelenggaraan pendidikan di masa sekarang ini menuntut adanya partisipasi masyarakat yang maksimal. Dalam UU Nomor 20 tahun 2003 pada salah satu misinya dijelaskan agar memberdayakan masyarakat dalam penyelenggaraan pendidikan berbasis otonomi daerah, kemudian masyarakat berperan dalam peningkatan mutu pelayanan pendidikan yang meliputi perencanaan, pengawasan, dan evaluasi program pendidikan melalui dewan pendidikan atau Komite Sekolah. Maka keberadaan Komite Sekolah harus menjadi kekuatan dan faktor pendorong terbentuknya mutu pendidikan. Hal tersebut dapat diwujudkan apabila kepala sekolah mampu menggandeng Komite Sekolah dalam merencanakan, melaksanakan, mengembangkan serta menilai program-program sekolah.

Adanya pembentukan Komite Sekolah, masyarakat akan merasa memiliki sekolah. Karena komite sekolah berperan sebagai wadah dan tempat menyalurkan aspirasi masyarakat dalam melahirkan kebijakan operasional dan program pendidikan di satuan pendidikan. Tetapi dikarenakan kurangnya pemahaman terhadap tujuan didirikannya Komite Sekolah menyebabkan peran Komite Sekolah hanya terpaku pada masalah pembangunan dan biaya pendidikan saja. Hal ini, mengakibatkan Komite Sekolah menjadi kurang respon terhadap berbagai program yang dihasilkan oleh sekolah karena terkadang komite jarang dilibatkan dalam penyusun program sekolah. Agar peran serta masyarakat dapat diberdayakan dan ditingkatkan, maka sekolah harus dapat membina kerja sama dengan orang tua dan masyarakat, menciptakan suasana kondusif dan menyenangkan bagi peserta didik serta warga sekolah. Gagasan untuk melibatkan masyarakat dalam konsep Komite Sekolah, merupakan suatu inisiatif dalam rangka memajukan sekolah, agar tidak ada persepsi yang menyatakan bahwa Komite Sekolah sebagai wakil orangtua siswa dan masyarakat hanya memberikan peran berupa materi. 
Oleh karena itu untuk dapat melaksanakan peran dan fungsinya dalam pencapaian mutu pedidikaan komite sekolah harus menyusun program kerja atau sebuah perencanaan program atau dalam hal ini Komite Sekolah membutuhkan pengelolaan yang baik agar dapat mewujudkan tujuan-tujuan yang telah direncanakan bersama sekolah. Pengelolaan Komite Sekolah merupakan suatu cara untuk mengatur sebuah program, mulai dari perencanaan, pengorganisasian, pelaksanaan, dan evaluasi, dengan memanfaatkan sumber daya yang ada dalam rangka memaksimalkan peran dan fungsi Komite Sekolah agar tujuan dibentuknya Komite Sekolah dapat tercapai secara efektif dan efisien.

\section{KAJIAN TEORI}

\section{Pengertian Komite Sekolah}

Komite Sekolah merupakan nama baru pengganti Badan Pembantu Penyelenggara Pendidikan (BP3). Secara umum kedua istilah tersebut tidak begitu mengalami perbedaan yang membedakan hanya terletak pada pengoptimalan peran serta masyarakat dalam mendukung dan mewujudkan mutu pendidikan. Berdasarkan UU SISDIKNAS (2002:112) komite sekolah adalah badan mandiri yang mewadahi peran serta masyarakat dalam rangka meningkatkan mutu, pemerataan, dan efisiensi pengelolaan pendidikan di satuan pendidikan baik pada pendidikan internal sekolah maupun pendidikan di luar sekolah. Pembentukkan Komite Sekolah telah ditetapkan dalam keputusan Mendiknas No.044/U/2002 diharapkan sasaran yang akan dicapai dalam perbaikan mutu pada program pembinaan pendidikan dasar dan menengah diantaranya agar terwujudnya manajemen pendidikan yang berbasis sekolah/ masyarakat dengan mengenalkan konsep dan pemberdayaan Komite Sekolah di setiap sekolah. Tujuan dibentuknya Komite Sekolah sebagai suatu organisasi masyarakat sekolah adalah sebagai berikut:

a. Mewadahi dan menyalurkan aspirasi serta prakarsa masyarakat dalam melahirkan kebijakan operasional dan program pendidikan di satuan pendidikan.

b. Meningkatkan tanggung jawab dan peran serta masyarakat dalam penyelenggaraan pendidikan di satuan pendidikan.

c. Menciptakan suasana dan kondisi transparan, akuntabel, dan demokratis dalam penyelenggaraan dan pelayanan pendidikan yang bermutu di satuan pendidikan 
Dari kutipan di atas keberadaan komite sekolah diharapkan dapat mengakomodir aspirasi masyarakat dan menyadarkan masyarakan atas peran serta dalam penyelenggaraan pendidikan dan terciptanya kondisi transparan dan akuntable dan demokratis. Peningkatan partisipasi dimaksudkan terciptanya lingkungan yang terbuka dan demokratis, dimana warga sekolah (karyawan, staf, guru, siswa) dan masyarakat (orang tua siswa, tokoh masyarakat, usahawan, dan sebagainya) dapat terlibat langsung dalam proses penyelenggaraan pendidikan.

Adapun fungsi Komite Sekolah menurut UU Sisdiknas (2003: 122) sebagai berikut:

a. Mendorong tumbuhnya perhatian dan komitmen masyarakat terhadap penyelenggaraan pendidikan yang bermutu.

b. Melakukan kerjasama dengan masyarakat (perorangan/organisasi/ dunia usaha/dunia industri) dan pemerintah berkenaan dengan penyelenggaraan pendidikan yang bermutu.

c. Menampung dan menganalisis aspirasi, ide, tuntutan, dan berbagai kebutuhan pendidikan yang diajukan oleh masyarakat.

d. Memberikan masukan, pertimbangan, dan rekomendasi kepada satuan pendidikan mengenai: 1) kebijakan dan program pendidikan 2) Rencana anggaran pendidikan dan belanja sekolah (RAPBS) 3) Kriteria kinerja satuan pendidikan 4) Kriteria tenaga kependidikan 5) Kriteria fasilitas pendidikan, dan 6) Hal-hal lain yang terkait dengan pendidikan.

e. Mendorong orang tua dan masyarakat berpartisipasi dalam pendidikan guna mendukung peningkatan mutu dan pemerataan pendidikan.

f. Melakukan evaluasi dan pengawasan terhadap kebijakan, program, penyelenggaraan, dan keluaran pendidikan di satuan pendidikan.

\section{Peran Komite Sekolah}

Pendidikan adalah tanggung jawab bersama antara orang tua, masyarakat dan pemerintah. Namun sampai saat ini lebih banyak bersifat slogan dan masih jauh dari harapan yang sebenarnya. Bisa dikatakan tanggung jawab stakeholder masih belum optimal, terutama peran serta masyarakat yang sampai saat ini masih dirasakan belum banyak diberdayakan. Di dalam UU Sisdiknas (2003:27) dikemukakan : 
a. Peran serta masyarakat dalam pendidikan meliputi peran serta perorangan, kelompok, keluarga, organisasi profesi, pengusaha, dan organisasi kemasyarakatan dalam penyelenggaraan dan pengendalian nutu pelayanan pendidikan.

b. Masyarakat dapat berperan serta sebagai sumber, pelaksana dan pengguna hasil pendidikan.

\section{Hubungan Sekolah dengan Komite (Masyarakat)}

Sekolah bukanlah suatu lembaga yang terpisah dari masyarakat karena sekolah merupakan lembaga yang bekerja dalam konteks sosial yang mengambil siswanya dari masyarakat, sehingga keberadaannya tergantung dari dukungan sosial dan finansial masyarakat. Oleh karena itu, hubungan sekolah dan masyarakat merupakan salah satu komponen penting dalam keseluruhan penyelenggaraan pendidikan.

Menurut Kindred leslie dalam Piet (1994:233) mengatakan hubungan sekolah dan masyarakat dengan tujuan meningkatkan pengertian anggota masyarakat tentang kebutuhan dari praktek pendidikan serta mendorong minat dan kerjasama para anggota masyarakat dalam rangka usaha memperbaiki sekolah. Adanya hubungan yang harmonis antar sekolah dan masyarakat yang diwadahi dalam organisasi komite sekolah diharapkan mampu mengoptimalkan peran serta orang tua murid dan masyarakat dalam memajukan program pendidikan.

Lebih lanjut Wahjosumijo (2010:334) berpendapat bahwa tujuan pokok pengembangan hubungan efektif dengan masyarakat adalah untuk memungkinkan orang tua dan warga wilayah berpartisipasi aktif dan penuh arti di dalam kegiatan sekolah. Maka dari pendapat tersebut menekankan komunikasi antara sekolah dan masyarakat sangat diperlukan.

Seperti yang dikatakan oleh Kindred Leslie yang dikutip oleh Mulyono (2010:208) menyatakan bahwa hubungan sekolah dengan masyarakat adalah suatu proses komunikasi antara sekolah dan masyarakat dengan tujuan meningkatkan pengertian anggota masyarakat tentang kebutuhan dari praktik pendidikan serta mendorong minat dan kerjasama para anggota masyarakat dalam rangka usaha memperbaiki sekolah.

Menurut Sagala (2013:251) hal tersebut akan mampu mengoptimalkan peran orang tua dan masyarakat dalam memajukan program pendidikan dan menciptakan 
proses pengajaran dan pembelajaran yang kondusif dan menyenangkan. Adanya komunikasi yang baik diharapkan akan terciptanya hubungan yang harmonis antar sekolah dan masyarakat yang diwadahi dalam organisasi Komite Sekolah yang saling bersinergis.

\section{Pengertian Mutu}

Mutu erat kaitannya tentang penilaian seseorang terhadap sebuah produk barang atau jasa. Suatu barang yang bermutu pasti mempunyai manfaat lebih bagi seseorang yang telah menggunakannya dan sesuai dengan kebutuhaan atau harapan. Sedangkan jasa yang bermutu adalah pelayanan yang diberikan seseorang atau organisasi yang sangat memuaskan. Mutu adalah salah satu tujuan pencapaian bagi organisasi atau lembaga yang bergerak pada bidang perdagangan atau jasa, karena mutu bisa menjadi tolak ukur keberhasilan bagi organisasi atau lembaga. Namun pada kenyataannya pandangan setiap orang terhadap mutu dapat berbeda, hal ini karena mutu yang sifatnya relatif bisa berbeda pada setiap pandangan atau pemikiraan seseorang dan dapat berubah-ubah.

Menurut Edward (2012:29) mengatakan bahwa mutu dianggap sebagai suatu hal yang membingungkan dan sulit untuk diukur, mutu menurut pandangan seseorang terkadang bertentangan dengan mutu dalam pandangan orang lain

Lebih lanjut oleh Crosby dalam Engkoswara (2012:304) berpendapat mutu adalah kesesuaian individual terhadap persyaratan/tuntutan. Dari beberapa pendapat di atas mempunyai kesamaan persepsi yaitu sifat mutu yang dinamis, relatif, karena pandangan setiap orang dapat berbeda dan dapat berubah-ubah.

\section{PEMBAHASAN}

\section{Peran Komite Sekolah Sebagai Pemberi Pertimbangan}

Peran komite sekolah sebagai pemberi pertimbangan, pelaksanaannya sejauh pengamatan peneliti dalam bentuk pemberian masukan dalam hal sarana dan prarana, pengelolaan pendidikan, memberikan masukan terkait RAPBS, meberikan masukan seperti pelaksanaan program atau kegiatan sekolah. Salah satu bentuk nyata yaitu saat proses akreditasi sekolah, komite dan sekolah saling bekerjasama. Bentuk kerjasama komite yaitu memberikan masukan dan dukungan menyiapkan dokumen pendukung agar memperoleh hasil memuaskan. 


\section{Peran komite Sekolah Sebagai Pendukung}

Selain itu peran komite sebagai pendukung sekolah baik dalam pencapaian tujuan sekolah dan dalam meningkatkan mutu pendidikan. Dukungan yang diberikan komite sekolah berupa materil dalam bentuk sarana yang belum ada disekolah dan dibutuhkan oleh sekolah seperti penyediaan sarana untuk kegiatan ekstrakurikuler di sekolah. Melakukan koordinasi dukungan dana dari orang tua murid ke sekolah, dan mengevaluasi pelaksanaan dukungan anggaran sekolah.

\section{Peran Komite Sekolah Sebagai Pengontrol}

Peran komite sebagai pengontrol ditunjukan dalam bentuk pengawasan terhadap proses pengambilan keputusan di sekolah, melakukan kontrol terhadap kualitas kebijakan yang diambil sekolah, melakukan pengawasan terhadap proses dan kualitas perencanaan dan program sekolah, dan melakukan pengawasan terhadap partisipasi sekolah pada program sekolah.

Selain itu komite sekolah juga berperan serta dalam rangka transparansi penggunaan alokasi dana pendidikan termasuk dalam mengawasi penggunaan dana bantuan dari pusat yang mengalir ke sekolah agar lebih dapat dipertanggungjawabkan. Penggunaan dana baik yang berasal dari donatur maupun pemerintah dapat benarbenar efektif dan termonitor alokasinya, apakah sesuai dengan Rancangan Anggaran Pendapatan dan Belanja Sekolah (RAPBS) .

\section{Peran Komite Sekolah Sebagai Mediator}

Peran komite sebagai mediator wujudnya berupa penghubung antara kepala sekolah dengan masyarakat, kepala sekolah dengan dewan pendidikan serta kepala sekolah dengan sekolah itu sendiri dalam hal ini Guru, staf karyawan dan murid, selain itu komite juga ikut serta dalam membuat usulan kebijakan dan beberapa program pendidikan kepada sekolah. Menjadi penampung aspirasi masyarakat dalam hal ini berupa pengaduan dan keluhan terhadap kebijakan dan program pendidikan dan menyampaikannya keluhan kepada sekolah.

Dengan adanya peran komite sekolah sebagai mediator antara sekolah dengan masyarakat maka akan mempermudah masyarakat dalam menyalurkan apa saja yang menjadi aspirasi mereka, dan apa yang menjadi aspirasi dari masyarakat dapat 
dijadikan masukan untuk sekolah sehingga sekolah dapat mengoreksi apa saja kekurangan yang ada disekolah dan secara bersama-sama dengan masyarakat.

\section{SIMPULAN}

Dapat disimpulkan bahwa sekolah bukanlah suatu lembaga yang terpisah dari masyarakat karena sekolah merupakan lembaga yang bekerja dalam konteks sosial yang mengambil siswanya dari masyarakat, sehingga keberadaannya tergantung dari dukungan sosial dan finansial masyarakat. Oleh karena itu, hubungan sekolah dan masyarakat merupakan salah satu komponen penting dalam keseluruhan penyelenggaraan pendidikan.

Oleh karena itu keterlibatan masyarakat sangat penting sebagai sumber aspirasi dan tolak ukur pencapaaian mutu. Konsep ini cenderung disambut dan diapresiasi sebagai sebuah angin segar dalam proses perjalanan penyelenggaraan lembaga pendidikan dengan lebih mengintensifkan pelibatan masyarakat hal tersebut muncul ketika pemerintah menerapkan sistem desentralisasi pendidikan. Konsep Tersebut mendorong komite Sekolah dan masyarakat menjadi kesatuan dan saling melengkapi, bahkan dapat memberikan suatu warna terhadap perumusan mutu di sekolah.

\section{DAFTAR PUSTAKA}

Arcaro Jerome S. 2007. Pendidikan Berbasis Mutu. Yogyakarta: Pustaka Pelajar.

Engkoswara. 2012. Administrasi Pendidikan. Bandung: Afabeta.

Mulyono. 2010. Manajemen Administrasi \& Organisasi Pendidikan. Jogjakarta: ARuzz.

Sagala Syaiful. 2013. Kemampuan Profeesional Guru Dan Tenaga Kependidikan. Bandung: Alfabeta.

Sahertian Piet. 1994. Dimensi-Dimensi Adminstrasi Pendidikan Di Sekolah. Surabaya: Usaha Nasional.

Sallis Edward. 2012. Total Quality Management In Education. Jogjakaarta: Ircisod. Wahjosuidjo. 2010. Kepemimpinan Kepala Sekolah. Jakarta: Rajagrafindo Persada. 